\title{
TanDEM-X: A SINGLE-PASS SAR INTERFEROMETER FOR GLOBAL DEM GENERATION AND DEMONSTRATION OF NEW SAR TECHNIQUES
}

\author{
Manfred Zink, Markus Bachmann, Benjamin Bräutigam, Thomas Fritz, \\ Irena Hajnsek, Gerhard Krieger, Alberto Moreira, Birgit Wessel \\ German Aerospace Center (DLR), Microwaves and Radar Institute \\ Oberpfaffenhofen, Germany, E-Mail: manfred.zink@dlr.de
}

\begin{abstract}
TanDEM-X (TerraSAR-X add-on for Digital Elevation Measurements) is an Earth observation radar mission that consists of a SAR interferometer built by two almost identical satellites flying in close formation [1]-[4]. With a typical separation between the satellites of 120 to $500 \mathrm{~m}$ a global Digital Elevation Model (DEM) with $2 \mathrm{~m}$ relative height accuracy at $12 \mathrm{~m}$ posting is being generated. While the main mission phase for DEM data acquisition has been finished in 2014, the processing of the global TanDEM-X DEM will be concluded mid-2016. Final DEMs for more than $65 \%$ of all land masses are already available for scientific and commercial applications. A 15-month science phase of the TanDEM-X mission started in October 2014 which offers the opportunity to explore the generation of DEMs with even higher accuracy for selected areas, and to demonstrate the capabilities of this unique mission for new scientific applications.
\end{abstract}

Index Terms - TanDEM-X, bistatic SAR formation, SAR interferometry, global Digital Elevation Model (DEM)

\section{MISSION OBJECTIVES}

The primary objective of the TanDEM-X mission is the generation of a global Digital Elevation Model (DEM) of the Earth's surface with unprecedented accuracy as the basis for a wide range of commercial applications as well as for scientific research [1]. It is expected that this data set will become a new reference in geosciences and remote sensing applications since its 3-D information content is ca. 30 times more accurate than the presently available global scale DEM data set (see Fig. 1).

TanDEM-X has an ambitious time schedule to reach its main mission goal. After the commissioning phase, the first four years were dedicated to the global DEM acquisitions. To facilitate dual-baseline phase unwrapping all land masses were covered at least twice in the same looking direction but with different baselines. Difficult mountainous terrain required additional acquisitions viewing from the opposite direction to allow filling gaps due to shadow and layover.
The main mission phase dedicated to DEM acquisition has been finished in 2014. By now final DEMs for more than $65 \%$ of the landmasses have been generated. The results achieved so far are well within the expected performance for the global DEM.
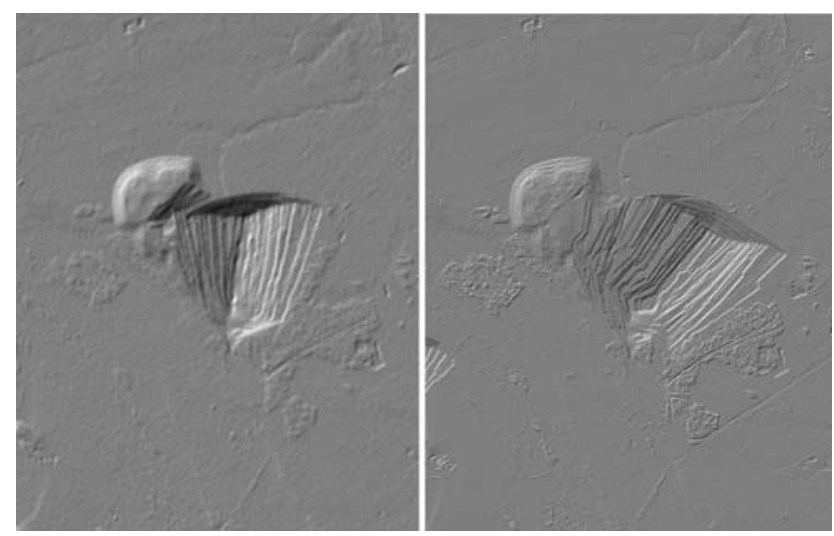

Fig. 1. Comparison of SRTM 1-arcsec DEM (left, acquired in 2000) and TanDEM-X DEM (right, 2011) of a coal mining area near Aachen/Germany showing the improved quality and the changes due to ten years of mining activity.

The baseline geometry in these first four years was optimized for DEM performance. A limited number of scientific acquisitions were included during this mission phase depending on the available satellite resources and the suitability of the baselines for fulfilling the scientific requirements. Since the start of the science phase in October 2014 the data acquisition and the baseline settings are dedicated to the secondary objectives of TanDEM-X. Beyond the generation of a global DEM, local DEMs of even higher accuracy level (posting of $6 \mathrm{~m}$ and relative vertical accuracy of $0.8 \mathrm{~m}$ ) and applications based on Along-Track Interferometry (ATI) like measurements of ocean currents are important secondary mission objectives. Furthermore, TanDEM-X supports the demonstration and application of new SAR techniques, with focus on multistatic SAR, polarimetric SAR interferometry, digital beam forming and super resolution. 


\section{KEY FEATURES OF THE TanDEM-X SYSTEM}

The TDX satellite is a rebuild of TSX with only minor modifications. This offers the possibility for a flexible share of operational functions for both the TerraSAR-X and TanDEM-X missions among the two satellites [5]. The TSX and TDX satellites were designed for a nominal lifetime of 5.5 years. Predictions based on the current status of system resources indicate several extra years of lifetime for both satellites and joint operation.

An orbit configuration based on a Helix geometry has been selected for safe formation flying. The Helix like relative movement of the satellites along the orbit is achieved by a combination of an out-of-plane (horizontal) orbital displacement imposed by different ascending nodes with a radial (vertical) separation imposed by different eccentricities and arguments of perigee. Cross- and alongtrack baselines ranging from $120 \mathrm{~m}$ to $10 \mathrm{~km}$ and from 0 to several $100 \mathrm{~km}$, respectively, can be accurately adjusted depending on the measurement requirement [6].

The missions TerraSAR-X and TanDEM-X jointly share the same space segment consisting of the TSX and TDX satellites and are operated using a common ground segment, that was originally developed for TerraSAR-X and that has been extended for the TanDEM-X mission [7], [8]. Specific new developments are:

- The spatial baseline between the TSX and TDX is derived from measurements taken by the dual-frequency IGOR GPS receivers and calibrated to millimeter accuracies using interferometric acquisitions over wellknown reference sites.

- Key issue in jointly operating both missions are the different acquisition scenarios: Whereas TerraSAR-X requests are typically single scenes for individual scientific and commercial customers, the global DEM requires a global mapping strategy. This strategy has also to account for the current formation flying geometry.

- The two satellites downlink their data (up to now more than 400 TBytes) to a global network of ground stations: Kiruna in Sweden, Inuvik in Canada, and O'Higgins in Antarctica. After a brief quality check, the data are recorded on tape and shipped to DLR Oberpfaffenhofen for processing and archiving.

- The entire processing chain is a new TanDEM-X specific development. Major design drivers result from the acquisition strategy which requires the combination of several (global) coverages and application of multibaseline processing techniques based on supporting intermediate products [9]. Absolute height calibration relies on a selected set of reference points (approximately 100 per 1 by $1^{\circ}$ DEM tile) of the globally distributed elevation data provided by the laser altimeter from NASA's ICESat mission [10].

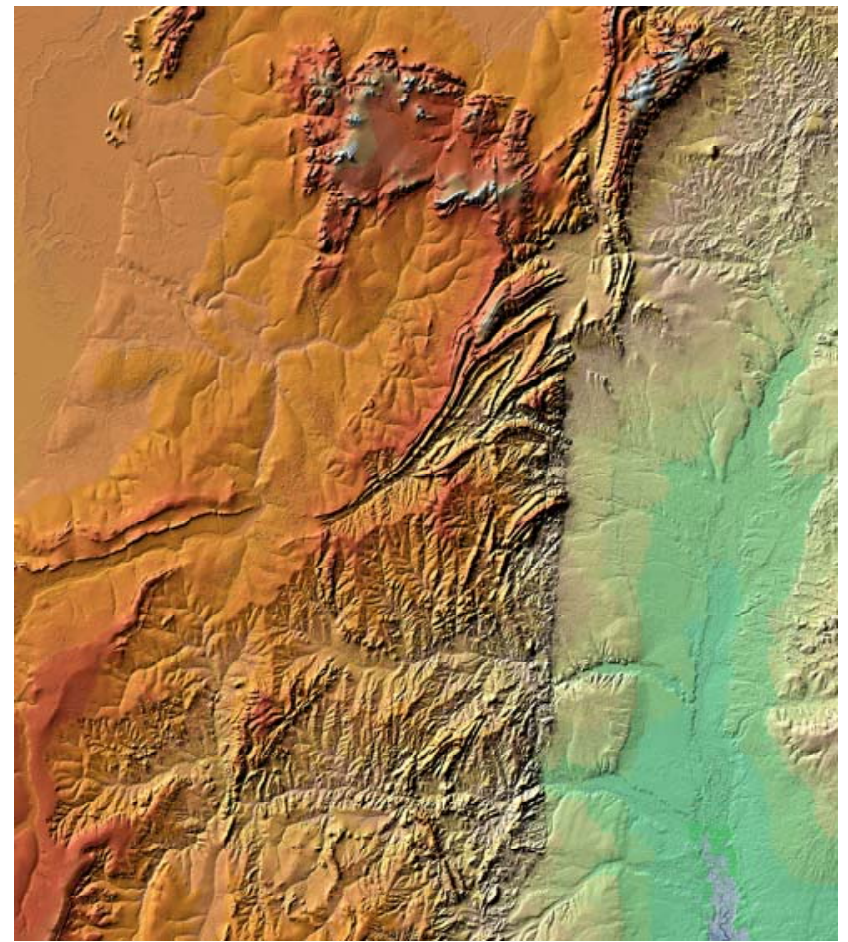

Fig. 2. Shaded relief of the TanDEM-X DEM near Isoka, Zambia.

\section{MISSION STATUS AND OUTLOOK}

After the launch in June 2010, the TDX SAR system was calibrated and its performance was verified to be as good as for TSX. Following comprehensive testing of the various safety measures close formation was achieved mid October 2010 and the operations at typical distances between 120 and $500 \mathrm{~m}$ is running remarkably smooth and stable since then.

The subsequent bistatic commissioning phase of the TanDEM-X mission was concentrated on checking out the complete bistatic chains from acquisition planning to bistatic and interferometric processing and generation of socalled Raw DEMs (long data takes are processed to scene based DEMs of 50 by $30 \mathrm{~km}$ extension). Global DEM acquisitions started in December 2010. Parallel to the first month of operational data acquisition the team concentrated its efforts on the calibration of the bistatic interferometer. Correction of differential delays between TSX and TDX was necessary to facilitate the utilization of radargrammetry for resolving the $2 \pi$-ambiguity band. Phase, delay and baseline calibration have reached such an accuracy level [11], that more than $90 \%$ of all Raw DEMs are within $\pm 10 \mathrm{~m}$ of DEMs derived from SRTM/ICESat data already before the final calibration step using ICESat data as reference heights. More than 500,000 Raw DEMs have been generated in a fully automated process employing multibaseline interferometric techniques. 
The first and second global coverages (except Antarctica) were completed in January 2012 and March 2013 respectively. After some gap-filling, Antarctica was mapped for the first time under local winter conditions. In early August 2013 the helix formation was changed to allow imaging of mountainous areas from the opposite viewing geometry [12]. Due to lack of SNR, desert areas had to be re-acquired as well, but at steeper incidence angles. Afterwards the satellites were maneuvered back to the original formation and Antarctica was covered again at larger baselines. The primary data acquisition program was concluded mid-2014. Since then gap-filling is being performed in parallel to the science phase.

Since the end of 2013 the final calibration and mosaicking chain is fully operational and as of May 2015 final DEM products for more than $65 \%$ of the total land surfaces are already available. So far the final DEMs are well within specification with outstanding absolute height accuracies in the order of $1.1 \mathrm{~m}(90 \%$ linear error, see Fig. 3) w.r.t. ICESat validation points (the majority of ICESat points not being used for DEM calibration). It is expected to complete the global DEM consisting of more than 19,000 1 by $1^{\circ}$ tiles by mid-2016 [13].

A comprehensive system has been established for continuous performance monitoring and verification [14], [15], [16] including feedback to the TanDEM-X acquisition planning for additional acquisitions. Fig. 3 shows as an example the absolute height accuracy ( $90 \%$ linear error) per tile derived from the comparison of the TanDEM-X heights against ICESat validation points (the majority of ICESat points not being used for DEM calibration). The cumulated absolute height error is with $1.1 \mathrm{~m}$ outstanding and one order of magnitude below the $10 \mathrm{~m}$ requirement.

Beyond the generation of a global TanDEM-X DEM as the primary mission goal, a currently running dedicated science phase is aiming at demonstrating the generation of even more accurate DEMs on local scales and applications based on along-track interferometry and new SAR techniques, with focus on multistatic SAR, polarimetric SAR interferometry, digital beamforming and super resolution [17].

As both satellites are still working very well and have plenty of resources left it is planned to continue the mission beyond 2015. A corresponding agreement between DLR und AIRBUS Defence \& Space is currently being prepared.

\section{CONCLUSION}

The TanDEM-X mission opens a new era in space borne radar remote sensing. A large single-pass SAR interferometer with adjustable baselines has been formed by adding a second, almost identical radar satellite to TerraSAR-X and flying both satellites in a closely controlled formation. This enables not only the acquisition of a global DEM with unprecedented accuracy, but also the demonstration of highly innovative bistatic and multistatic

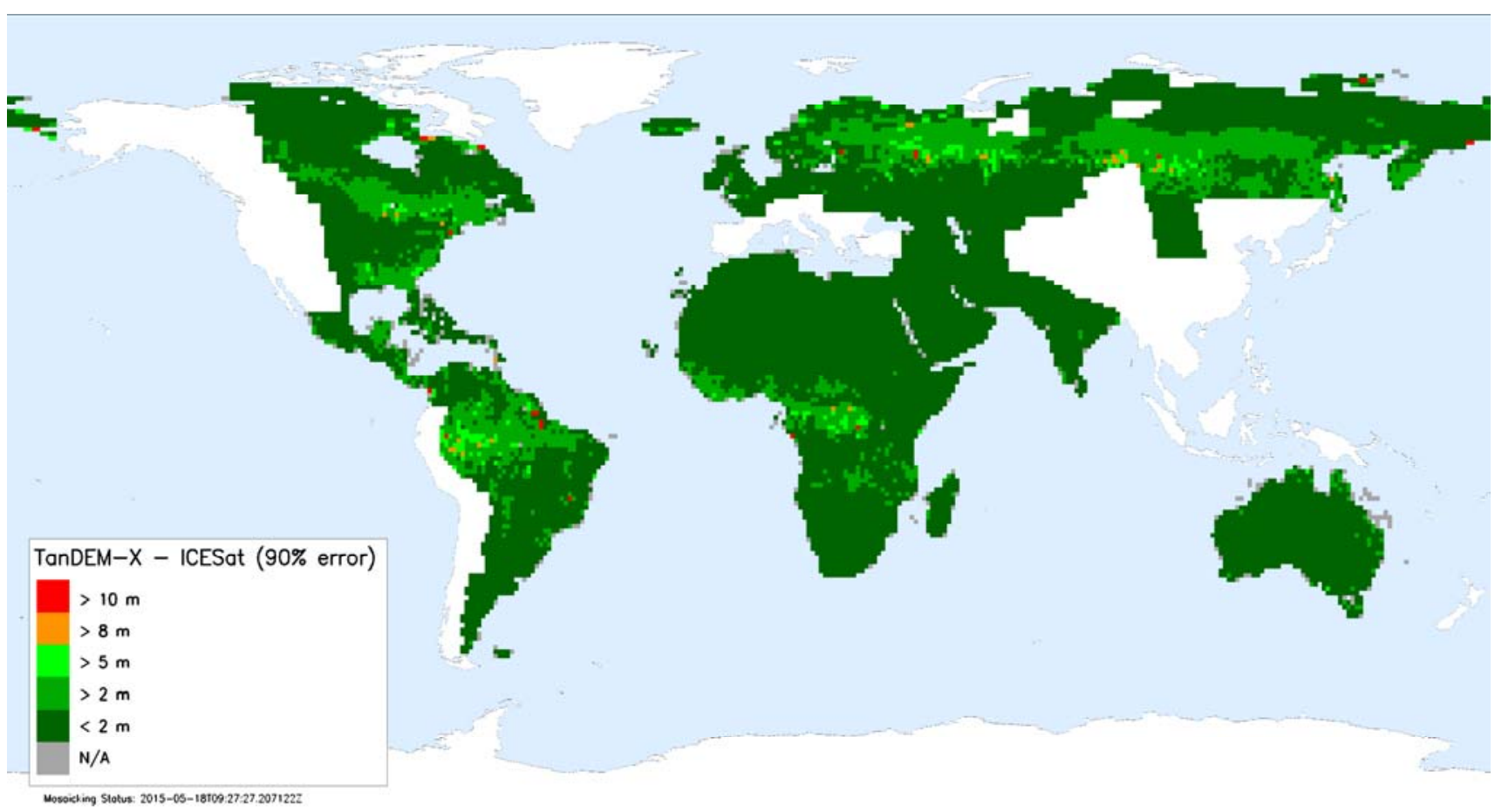

Fig. 3. TanDEM-X DEM production status as of May $18^{\text {th }}$, 2015: the absolute height accuracy (90\% linear error) is shown per 1 by $1^{\circ}$ DEM tile; the cumulated absolute height error is with $1.1 \mathrm{~m}$ one order of magnitude below the $10 \mathrm{~m}$ requirement. 
SAR techniques and applications. These experiments form the basis for future formation flying SAR missions.

Key technologies like close formation flying, bistatic SAR operation and synchronization, precise baseline estimation and calibration as well as sophisticated bistatic and interferometric processing chains have been implemented. Appropriate safety mechanisms enable safe operation at typical satellite distances between $120 \mathrm{~m}$ and $500 \mathrm{~m}$. The complete mission is fully operational since December 2010 and both satellites as well as the ground system perform remarkably well. Data acquisitions for the global DEM were finished in 2014. The current focus is on the processing of the global DEM data. More than $65 \%$ of the global land mass is already available as final DEM products. The global DEM will be available in 2016, and is expected to become a new reference for commercial (http://www.astrium-geo.com/en/168-tandem-x-global-dem) and scientific applications (http://www.dlr.de/HR/tandem-x) since its 3D information content is at least 30 times more accurate than the presently available global scale DEM data set.

Beyond the generation of a global TanDEM-X DEM as the primary mission goal, in October 2014 a science phase dedicated at demonstrating the generation of even more accurate DEMs on local scales and applications based on along-track interferometry and new SAR techniques, with focus on multistatic SAR, polarimetric SAR interferometry, digital beamforming and super resolution commenced. Within a 15 months period the science phase will offer a wide selection of baseline geometries and interferometric modes. After 2015 it is planned to continue with bistatic interferometry.

TanDEM-X has demonstrated the feasibility of an interferometric radar mission with close formation flight and delivers an important contribution for the conception and design of future SAR missions. One example is Tandem-L, a mission for monitoring dynamic processes on the Earth surface with unprecedented accuracy [18].

The TanDEM-X project is partly funded by the German Federal Ministry for Economic Affairs and Energy (Förderkennzeichen $50 \mathrm{EE}$ 1035).

\section{REFERENCES}

[1] Krieger, G., Moreira, A., Fiedler, H., Hajnsek, I., Werner, M., Younis, M., Zink, M.: TanDEM-X: A Satellite Formation for High Resolution SAR Interferometry. IEEE Transactions on Geoscience and Remote Sensing, vol. 45, no. 11, pp. 3317-3341, Nov. 2007.

[2] Zink, M., Bachmann, M., Bräutigam, B., Fritz, T., Hajnsek, I., Krieger, G., Moreira, A., Wessel, B.,: TanDEM-X: The New Global DEM Takes Shape. IEEE-GRSS Magazine, Vol. 2, No. 2, June 2014.

[3] Krieger, G. et al.: TanDEM-X. In: Distributed Space Missions for Earth System Monitoring, Chapter 13, Springer 2012, pp. $387-435$.

[4] Krieger, G., Hajnsek, I., Papathanassiou, K., Younis, M., Moreira, A.: Interferometric Synthetic Aperture Radar (SAR)
Missions Employing Formation Flying. Proceedings of the IEEE, vol. 98 , no. 5,2010 .

[5] Pitz, W., Miller, D.: The TerraSAR-X Satellite. IEEE Transactions on Geoscience and Remote Sensing, vol. 48, no. 2, pp. 615-622, Feb. 2010.

[6] R. Kahle, B. Schlepp, S. Aida, M. Kirschner, M. Wermuth, "Flight Dynamics Operations of the TanDEM-X Formation", SpaceOps 2012, Stockholm, Schweden, June 2012.

[7] Buckreuss, S., Schättler, B., The TerraSAR-X Ground Segment, IEEE Transactions on Geoscience and Remote Sensing, vol. 48, no. 2, pp. 623-632, 2010.

[8] Schättler, B., Kahle, R., Metzig, R., Steinbrecher, U., The Joint TerraSAR-X/TanDEM-X Ground Segment, Proc. IGARSS 2011, pp. 2298 - 2301, IEEE, 24.-29. Jul 2011, Vancouver, Canada.

[9] T. Fritz, H. Breit, C. Rossi, U. Balss, M. Lachaise, U. Duque, "Interferometric Processing and Products of the TanDEM-X Mission," International Geoscience and Remote Sensing Symposium (IGARSS), Munich, Germany, 2012.

[10] B. Wessel, et.al.,"Design of the DEM Mosaicking and Calibration Processor for TanDEM-X.", European Conference on Synthetic Aperture Radar (EUSAR), Friedrichshafen, Germany, 2008.

[11] J. Hueso González, J. Walter Antony, M. Bachmann, G. Krieger, M. Zink, D. Schrank, M. Schwerdt, "Bistatic System and Baseline Calibration in TanDEM-X to Ensure the Global Digital Elevation Model Quality," ISPRS Journal of Photogrammetry and Remote Sensing, Vol. 73, pp. 3-11, 2012.

[12] D. Borla Tridon, et.al., "TanDEM-X: DEM Acquisition in the Third Year Era", Int. Journal of Space Science and Engineering, Vol. 1, No.4 pp. $367-381,2013$.

[13] B. Wessel, "TanDEM-X Ground Segment - DEM Products Specification Document", Public Document TD-GS-PS-0021, Issue 3.0, 2013.

[14] M. Martone, B. Bräutigam, P. Rizzoli, C. Gonzalez, M. Bachmann, G. Krieger, "Coherence Evaluation of TanDEM-X Interferometric Data," ISPRS Journal of Photogrammetry and Remote Sensing, Vol. 73, pp. 21-29, 2012.

[15] P. Rizzoli, B. Bräutigam, T. Kraus, M. Martone, G. Krieger, "Relative Height Error Analysis of TanDEM-X Elevation Data," ISPRS Journal of Photogrammetry and Remote Sensing, Vol. 73, pp. 30-38, 2012

[16] B. Bräutigam, P. Rizzoli, M. Martone, M. Bachmann, T. Kraus, G. Krieger, "InSAR and DEM Quality Monitoring of TanDEM-X,“ International Geoscience and Remote Sensing Symposium (IGARSS), Munich, Germany, 2012.

[17] Hajnsek, I., Busche, T., Announcement of Opportunity: TanDEM-X Science Phase, TD-PD-PL-0032, 19-May-2014, available at: https://tandemX-science.dlr.de/

[18] Moreira, A. Hajnsek, I., Krieger, G., Papathanassiou, K., Eineder, M., De Zan, F., Younis, M., Werner, M.; Tandem-L: Monitoring the Earth's Dynamics with InSAR and Pol-InSAR. Proceedings of the PolInSAR Workshop, Frascati, Italy, 2009. 